\title{
Investigation of the Wear Behavior of Abrasive Grits in a Dry Machining Inconel 718 Narrow-Deep- Groove with a Single-Layer Cubic Boron Nitride Grinding Wheel
}

\section{Guang Li}

Taiyuan University of Technology

Guoxing Liang ( $\sim$ liangguoxing@tyut.edu.cn )

Taiyuan University of Technology https://orcid.org/0000-0003-2665-2341

\section{Xingquan Shen}

North University of China

\section{Ming Lv}

Taiyuan University of Technology

Donggang Liu

Taiyuan University of Technology

\section{Xinhui Hao}

Taiyuan University of Technology

\section{Yonggui Huang}

Taiyuan University of Technology

\section{Tochukwu Ojiako Princewill}

Taiyuan University of Technology

\section{Mohammed Al-Nehari}

Taiyuan University of Technology

\section{Research Article}

Keywords: Electroplated cBN, Wear behavior, Dry grinding, Cleavage fracture, Narrow-deep-groove

Posted Date: March 22nd, 2021

DOl: https://doi.org/10.21203/rs.3.rs-334969/v1

License: (c) (1) This work is licensed under a Creative Commons Attribution 4.0 International License. Read Full License 
Version of Record: A version of this preprint was published at The International Journal of Advanced Manufacturing Technology on August 4th, 2021. See the published version at https://doi.org/10.1007/s00170-021-07823-8. 


\section{Abstract}

The wear behavior of a single-layer electroplated cubic boron nitride (cBN) grinding wheel was investigated in creep feed profile grinding Inconel 718 narrow-deep-groove with a width of $2 \mathrm{~mm}$. In this paper, the protrusion height of $\mathrm{CBN}$ grits on the side edge of the grinding wheel was measured by threedimensional optical profiler, and a scanning electron microscope was used to detect the topography of worn cBN grit and the nickel bonding layer. The investigation results indicated that the steady wear stage of the grinding wheel shared more than $84.6 \%$ of the wheel lifespan, and the machining precision of the grinding wheel was kept at a high level. The fracture mode of the $\mathrm{CBN}$ grit was proven to be cleavage. The source of the cleavage cracks was observed on the surface of wear flat or the side surface of the cBN grit. The holding strength of $\mathrm{cBN}$ grit could be weakened due to the joint surface breakage, the displacement of grit, or the cracks of the nickel bonding layer. The transition layer was contributed to the decrease of the bonding strength. Severe macro fractures and the concentration of pulled out grits were observed on the transition edge and the inner area of the side edge, separately. This study provides a deep understanding of the wear mechanism of a single-layer electroplated cBN grinding wheel.

\section{Introduction}

Nickel superalloys are widely used in the aeronautical engineering field due to their high thermal stability, fatigue resistance, high-temperature strength, and corrosion resistance. Nickel superalloys are applied in aero-engine components such as turbine discs, turbine blades, and the engine cabins of aero-engines [13]. However, due to their high strengths at elevated temperatures, high work hardening, and low thermal diffusivity, nickel-based superalloys are categorized as difficult-to-machine materials [4]. The root of the NDG matching of a turbine blade is characterized by the depth-to-width ratio exceeding 2 and the groove width being smaller than $4 \mathrm{~mm}$. The methods for machining a component of NDG, in the order of the traditional processes, include milling a groove, quenching, and grinding with a normal abrasive wheel. In particular, it is inevitable for the wheel to experience extreme wear and larger roughness of the ground surface, and thermal damage often occurs in the profile grinding process, with its industrial application being constrained. As a super abrasive machining tool, a single-layer cBN grinding wheel provides a potential way to fabricate this type of material with the structure of the NDG contributing to its high hardness, high thermal and chemical stability, and excellent wear resistance. A single-layer cBN wheel usually exhibits higher bonding strength, larger grit protrusion, and acceptable grit distribution, which is suitable for grinding a groove with a larger depth of cut $[5,6]$. In addition to the creep feed in the grinding process, the grinding force can be decreased, for which an NDG with a high-quality surface is easily implemented. Thermal damage can be hardly induced due to the reduced thickness of the chip formation. Therefore, a single-layer cBN grinding tool is widely employed in machining parts with nickel-based superalloys [7-9]. Generally, single-layer cBN wheels containing a metal bond layer are fabricated by brazing and electroplating. The fabricated temperatures of electroplated $\mathrm{CBN}$ grinding wheels are lower than those of brazed cBN grinding wheels, and small amounts of residual stress and deformation tolerance can be introduced in the preparation [10]. Thus, creep feed grinding with a single-layer 
electroplated $\mathrm{CBN}$ grinding wheel is considered to be one of the most suitable technologies for machining a NDG with nickel superalloy. However, the difficult-to-machine behavior of nickel superalloys coupled with the large rate of the depth-to-width leads to cBN grit wear occurring in the grinding process. The precision of the parts is decreased due to the grit wear and when the grit wear of the grinding wheel reaches a certain level, the topography of the wheel experiences progressive alterations, and the poor grinding performance becomes a major challenge. In recent years, significant research attention has been drawn towards the wheel wear mechanism and the grinding behavior with respect to controlling the wear behavior and effective grinding. The wear characteristics of the grit at the cutting edges during grinding are the main factor dominating the service life of grinding wheels. Recent studies have indicated that the wheel wear progression consists of an initial transient period and a steady-state period. At the initial transient period, the radial wheel wear rate progressively decreases, and it is mainly dominated by the pullout of weakly held grits. The wear characteristic is kept at a steady-state period when the radial wear rate remains constant, and the main wear mode is grit fracture. Attrition and fracture lead to the grit edges being dull, which increases the grinding power [11]. Similar results of $\mathrm{CBN}$ wear progression were drawn in the latest publication, in which the effects of the grit roughness and the nickel plating thickness on the wear behavior were investigated. Further experiment results indicated that an accelerating wear regime occurred towards the end of the wheel life from the wheel tested up to failure. Also, the wear progression of the wheel was classified as the initial high wear rate regime, steady-state regime, and accelerating wear regime [12]. The wear behavior of a randomly selected cBN grit was observed in grinding process. It was claimed that the wear progression of the cBN grit was micro attrition wear, extreme attrition wear, and a micro fracture. The main grit wear patterns generated in grinding were attrition wear, grit fracture, and chip adhesion. The wear of the $\mathrm{CBN}$ wheel was quantitatively evaluated by using the percentage of the wear flat area. The area percentage of the wear flat on the grinding wheel could be kept to an acceptable level. High wear resistance has been presented in the high-speed grinding of an Inconel 718 [13]. The protrusion height of $\mathrm{CBN}$ grit in terms of the wheel failure was studied. The evolution of the grit protrusion height had a distribution that changed from unimodal to bimodal. The wheel worn modes were the grit pullout, attrition, and fracture. The grits with the highest protrusion were pulled out rapidly, which resulted in the redistribution of the grinding force around their surroundings. The attrition and fracture wear were triggered as the load arose on the grits. It could be said that the grit wear rate primarily depended on the workpiece feed rate rather than a grinding wheel rotation [14]. During the grinding of Inconel 718 nickel superalloy with an electroplated CBN wheel, the radial wheel wear and the wear modes were evaluated with the advance of the accumulated material removal. The cBN grit wear progression was divided into the initial transient region, the steady-state region, and the failure region. With the increase in accumulated material removal, the wear behavior of the grinding wheel was displayed with the sequence of the grit pullout, small attrition wear, micro fracture, large attrition wear, and macro fracture. The grinding wheel was dull due to the work material intensely adhering among the gap of the grits and the occurrence of critical attrition wear [15]. Mechanical stress-induced fracturing and thermal stress-induced fracturing were found in cBN grits after grinding Ti-6Al-4V titanium alloys [16]. The mechanisms of the mechanical stress fracturing and the thermal stress fracturing were analyzed. 
According to the results drawn in the literature mentioned above, the analysis of wheel wear is based on the process of surface grinding. Only the grits located on the circular surface are involved in the machining process, with the radial wear is uniformly distributed on the wheel surface. In the profile grinding process, the grinding loads are different due to the varied distribution of the stock allowance along the workpiece profile along the normal direction, which leads to the variations of the grinding force, grinding temperature, and wheel wear $[17,18]$. The blade root-mounting slots and fir tree blade root forms are the typical profile grinding components. Researchers have conducted profile grinding experiments by using diamond and $\mathrm{CBN}$ grinding wheels, as well as investigating the wheel wear mechanism, wheel dimensional accuracy, surface roughness, specific grinding energy, grinding temperature. The results showed that the specific grinding energy could stay at a low level by adjusting the grinding parameters [19]. The dimensional accuracy of the groove could meet the requirements of tolerance, and a fine surface integrity was obtained $[16,19]$. Wear flats, workpiece material adhesion, and micro fractures were induced in the profile grinding wheel. The wear modes varied from one location to another in the profile grinding wheels [18]. A finite element method was also applied to investigate the grinding temperature, and the grinding temperature was less than $120^{\circ} \mathrm{C}$ without grinding burn $[17,20]$. When grinding an NDG with the creep feed parameter, the whole volume of the groove material was removed. Compared with surface grinding or profile grinding, the magnitude of material removal was much larger for one grinding pass.

Previous studies clarified that the material remove methods of $c B N$ grits varied in different sections of the wheel edge during the profile grinding of an NDG. The different material removal methods resulted in the uneven distribution of wheel wear, which had negative effects on machining accuracy. Nevertheless, few studies have focused on the wheel wear in the grinding of an NDG. The investigations of the wear mechanisms occurring in a wheel based on the theory of grinding edge division have not yet been carried out sufficiently.

In this research, a single-layer electroplated cBN grinding wheel was employed to machine nickel superalloy NDG in creep feed grinding. Multiple experiments were carried out to investigate the wheel wear. Firstly, the grit protrusion height of a randomly selected area on a cBN grinding wheel was tested after each grinding pass, and the protrusion height distribution of the $\mathrm{CBN}$ grit was studied. The wear revolution of the grinding wheel was categorized in terms of the average grit protrusion height. Then the CBN grit wear modes at different grinding edges (top edge, side edge, and transition edge) were evaluated. The fracture mechanism of the $\mathrm{CBN}$ grits on the side edge was clarified. Finally, the wear behavior of the nickel bonding layer on the grinding wheel was analyzed. This study will help to provide a deep understanding of the mechanism of wheel wear and provide a way to machine an NDG.

\section{Experiment And Method \\ 2.1 Experiment setup}


The experiments for the NDG profile grinding with the single-layer electroplated cBN grinding wheel were conducted on a MV-40 precision vertical machining center and the spindle revolution was on a scale from $10 \mathrm{r} / \mathrm{min}$ to $10000 \mathrm{r} / \mathrm{min}$ (Fig. 1(a)). The grinding wheel diameter was $200 \mathrm{~mm}$ and the width was $2 \mathrm{~mm}$. The cBN abrasive with a grit size of 100-120 meshes was employed. Its distribution on the as-received grinding wheel is shown in Fig. 1(b). The cBN grits are uniformly distributed in the field of vision. The experimental parameters are shown in Table 1.Each NDG was formed in one grinding pass on a nickel superalloy workpiece. As shown in Table 2, the composition of Inconel 718 was analyzed using an energy dispersion spectrometry (EDS). The section shape of the NDG is shown in Fig. 1(c). The fillet radius of the NDG was detected with an M-800X optical microscope, and the average value of the corner radius located at the bottom was $0.458 \mathrm{~mm}$. The material removal volume in one grinding travel was $417.3 \mathrm{~mm}^{3}$.

Table 1

Experimental parameters

\begin{tabular}{|ll|}
\hline Wheel specification & Single-layer electroplated cBN wheel \\
\hline Grinding environment & Dry grinding \\
\hline Wheel size & Diameter: $200 \mathrm{~mm}$, width: $2 \mathrm{~mm}$ \\
\hline Wheel matrix material & AISI 1045 \\
Workpiece material & Inconel 718 \\
\hline Workpiece size & $30 \times 30 \times 20 \mathrm{~mm}^{3}$ \\
Wheel rotation & $4000 \mathrm{r} / \mathrm{min}$ \\
\hline Feed rate & $0.002 \mathrm{~m} / \mathrm{min}$ \\
\hline Depth of cut & $7 \mathrm{~mm}$ \\
\hline
\end{tabular}

Table 2

Chemical compositions (\%) of Inconel 718 nickel-base superalloy

\begin{tabular}{|llllllllllllll|}
\hline Element & Ni & Fe & $\mathbf{C r}$ & $\mathbf{N b}$ & Mo & $\mathbf{C}$ & $\mathbf{T i}$ & $\mathbf{0}$ & $\mathbf{A l}$ & $\mathbf{C o}$ & $\mathbf{M n}$ & $\mathbf{P}$ & $\mathbf{S}$ \\
\hline Value (wt \%) & 49.0 & 18.0 & 18.1 & 6.2 & 2.9 & 2.5 & 1.0 & 0.7 & 0.6 & 0.4 & 0.3 & 0.2 & 0.1 \\
\hline
\end{tabular}

\subsection{Experiment method}

The shape copying method is generally employed to measure the radial wear of an electroplated cBN wheel $[15,21]$, as indicated in Fig. 2. The width of the grinding wheel was larger than that of the workpiece, and this resulted in two steps being produced on both sides of the working surface in grinding 
process. The step of the worn wheel was copied through grinding soft steel with a width that was wider than the wheel width. Then the step height, considered as the radial wheel wear, appeared on the soft steel workpiece, and it was measured with a non-contact optical three-dimensional (3D) profiling system. The above-mentioned measurement is widely used in surface grinding. However, it is difficult to generate a wear step on a profile grinding wheel, and the shape coping method can rarely be employed in measuring wheel wear in the profile grinding process. Therefore, graphite samples were machined by worn profile grinding wheel, and the wear of the wheel profile was obtained using the measurement discrepancy of the profile of the graphite replicas in different wear stages [18, 22]. However, the progression of the graphite replicas doubled the machining time, especially in the creep feed grinding process. Both the shape copying method and the graphite replica method were indirect measurement methods. A higher efficiency method was essential for measuring the wear of the profile grinding wheel.

In this research, the cBN grit protrusion height was directly detected with a SM-1000 3D optical profiler. The wear of the profile grinding wheel was obtained using the difference value of the average grit protrusion height after each grinding travel. The measurement process of the $\mathrm{cBN}$ grit protrusion height is shown in Fig. 3. Three randomly selected zones on the side edge of the wheel with dimensions of 2 $\mathrm{mm} \times 2 \mathrm{~mm}$ were detected after each grinding pass. The reflection waveform of the detected zone on the grinding wheel was checked by manually moving the workbench (Fig. 3(b)). In order to focus well, the light intensity needed to be adjusted carefully until a good reflection waveform was observed. The professional software of Mountains Map ${ }^{\circledR}$ Scanning Topography was used to reconstruct the 3D profile of the detected zone on the grinding wheel (Fig. 3(c)). Then a small zone, including one cBN grit, could be extracted with the software. The 3D profile of the extracted zone containing the $\mathrm{CBN}$ grit is shown in Fig. 3(d). The accurate maximum protrusion height of the grit could be observed through the function of the Abbott curve in the software.

The computer numerical control wire-cut electric discharge machine was employed to cut the grinding wheel located at the $\mathrm{cBN}$ grit belt to prepare the sample. The wire-cut path was along the blue solid lines (Fig. 3(a)), and the radial cutting distance was $8 \mathrm{~mm}$. The central angle of each sample was $15^{\circ}$. The schematic diagram of the grinding wheel section is shown in Fig. 3(a). The grinding edges were divided into the top edge, the side edge, and the transition edge. The division theory of the grinding edges is discussed in Sect. 3.2.1.

The grinding wheel surface topography and the bonding section topography were detected with a scanning electron microscope (SEM). The micro topography of cBN grit was observed trough SEM. The line profile of the worn surface on cBN grit was detected through the software tool of Insert Line Profile. The profile graph was based on the gray scale of SEM image [23]. A line was drawn on the detected surface and the profile along this line would be observed. The line profile function can deal with basic profile analysis. 


\section{Results And Discussion}

\subsection{Wear evolution of the wheel surface based on the grit protrusion height}

The side surfaces of the NDG were the main work surfaces, such as the rotor groove of the vane pump and the fir groove of the turbine disc. The side surface was mainly ground by the side edge of the grinding wheel. Thus, the wear of the side edge on the grinding wheel was the key factor for the qualities of the NDG such as the side surface integrity and the dimension tolerance. The 3D geomorphology results of the side edge of the grinding wheel in the randomly selected area are displayed in Figs. 4(a1)(e1) and the grit height contours in 2D are also described (Figs. 4(a2)-(e2)). The characteristics of the grit height contours were basically consistent with uniform distribution, but the grit height uniformity tended to decrease as the accumulated material removal (AMR) grew in the grinding process. Additionally, the uniformly distributed grits were attached to the matrix of the fresh wheel (Fig. 4(a1), Fig. 4(a2)). The sharp cutting edges of the grit could be observed intuitively. The maximum protrusion height on the fresh wheel reached $129 \mu \mathrm{m}$. After different accumulated material removal volumes for the machining, the wear flats (marked with the arrows in Fig. 4) were generated on part of the grits after machining. A few pits coming from the grit pullouts (marked with dashed line circles) could also be found on the grinding wheel. Wear flats were induced on the grits and pulled-out grits were generated in the grinding process. Figures $4(\mathrm{a} 3)-(\mathrm{e} 3)$ present the statistical average frequency histograms for the grit protrusion height at the various AMR stages. It was clear that the numbers of the grit for the maximum protrusion height tended to decrease with the growth of the AMR. Figure 4(e1) shows the geomorphology of the grit distribution in the randomly selected area on the over-worn grinding wheel. Due to the pullouts and the attrition wear of the highest cBN grits, the frequency number of the highest protrusion height grits decreased with the increase in AMR (Fig. 4(e3)). The maximum grit protrusion height decreased to 99.2 $\mu \mathrm{m}$ and half of the $\mathrm{CBN}$ grits were nearly pulled out. Additionally, the protrusion height of the residual grits was much lower than that of the fresh wheel.

After each grinding pass, the grit protrusion height on the grinding wheel was tested in the grinding of the NDG. The detailed data depending on the variations of the AMR are shown in Fig. 5.

Based on both of the two figures (Fig. 5(a), Fig. 5(b)), it could be concluded that the average grit protrusion height decreased as the AMR grew. A visible transformation occurring for the average grit wear rates could be found for the AMR being up to the conditions of $V_{0}\left(V_{0}=834.6 \mathrm{~mm}^{3}\right)$ and $V_{1}\left(V_{1}=5424.9\right.$ $\mathrm{mm}^{3}$ ). Before the parameter of the AMR reached $V_{0}$, the extreme descent of the varying height of the grit protrusions implied that the initial wear stage was deemed to be occurring. The grinding process between $V_{0}$ and $V_{1}$ was identified to be a steady wear stage due to a smooth reduction rate of the protrusion height. The steady wear stage in the grinding NDG shared more than $84.6 \%$ of the wheel lifespan. For the grinding wheel, the maximum deviation of the average grit protrusion height was smaller than $3.1 \mu \mathrm{m}$ in the steady wear stage. Additionally, the tolerance grade of the NDG was less than IT5 (GB/T 1800.1- 
1997) with a width of $2 \mathrm{~mm}$. Therefore, the precision durability could be kept at a high level in the steady wear stage. When the AMR was over $v_{1}$, the grinding wheel could be considered to be the accelerating wear stage. It could be found that the average values of the protrusion height had a sudden decrease in this phase. During the initial wear stage for the grinding wheel, grits with higher protrusion height participated in the metal removal. Furthermore, only a small wheel-workpiece zone could be created in the processed region. This meant that a large mechanical load was applied on the higher protrusion grits and a rapid increase in wear rate was induced. A similar conclusion for surface grinding process was also pointed out in publication [15]. As the higher protrusion grits were worn out, more grits with lower protrusion heights were gradually involved in cutting the material. In addition, the wheel-workpiece contact area was expanded. This implied that the decrease of the load was exerted on a single grit. Therefore, the wear rate of the grits slowed down and the average values of the grit protrusion height declined [16]. The rubbing mode tended to rise and become dominant in the metal removal close to the finishing point of the grinding wheel. A large number of grits were processed with large-area wear flats. The grits were severely worn, which led to the average values of the protrusion height appearing to have a steep slope.

Figure 5(b) shows that the statistical results of the residual cBN grits, the grit pullouts, and the total number of grits depended on the variations of the AMR. The number of pulled out grits could be estimated according to the pits generated at a randomly selected area after each grinding pass. The accounting numbers were the average values derived from three detected consequences. The residual cBN grits decreased with the advance in the AMR, and the number of pits caused by pulled grits had an opposite variation. The total grit numbers of the $\mathrm{CBN}$ grits of the grinding wheel approximately remained constant. The fitting results showed that the linear trends of the residual $\mathrm{CBN}$ grits and the grit pullouts could be obtained with an increase in AMR. In the initial wear stage, only a small number of grits with a larger protrusion height participated in the cutting process. The grits penetrated deeply into the surface of the workpiece then the mechanical load was very high. Since single-layer grits on the wheel were concerned, the various grit sizes were approximately equal to a constant. Therefore, the higher the protrusion height of the grit was, the thinner the bonding layer became. It was reasonable to assume that the $\mathrm{cBN}$ grits with the highest protrusion height were weakly held in the bonding layer, and these grits were apt to be pulled out in metal removal. The number of active grits was enlarged when the highest protrusion $\mathrm{CBN}$ grits were pulled out. The loads that acted on each grit were decreased as the multiple grits were involved in the grinding with the risen area of the wear flat and dull edges on the grits, and these resulted in the increased grinding force. The experiment results showed that the grit pullout increase rate was kept constant. Thus, the increased force caused by the dulling grits became domination for the effects of the grit pullouts. When the process entered the accelerating wear stage, the wear flat expanded with the majority of the grits being worn. Then rubbing and flowing were the main machining modes, and the cutting depth was smaller than the un-worn wheels. A severe increase in the grinding force would not appear. Additionally, the residual cBN grits were bonded firmly, and a sharp increase in the number of pulled-out grits could not be found. A similar phenomenon for the grit pullout was also reported in the surface grinding [10]. 


\subsection{Grit wear behavior of single-layer electroplated cBN grinding wheel}

\subsubsection{Grit wear distribution of the worn single-layer electroplated cBN grinding wheel}

Based on the division theory of the grinding edges of the single-layer electroplated cBN grinding wheel, the grinding edges could be divided into the top edge, the side edge, and the transition edge. The schematic diagram of the grinding edge division of the single-layer electroplated cBN grinding wheel is shown in Fig. 6. Machining the NDG on the workpiece with the single-layer electroplated cBN grinding wheel was a typical profiled grinding process. About $90 \%$ of the material was removed by the cBN grits located at the top edge in the grinding of the NDG. Less than $10 \%$ of the material removal was conducted by the transition edge and the side edge. The material removal process of the $\mathrm{CBN}$ grits could be categorized into three phases, namely, the rubbing period, ploughing period, and cutting period. The grits bonded on the top edge had a larger depth of cut compared with the grits located at the transition edge and the side edge. Three phases of rubbing, ploughing, and cutting were experienced in the metal removal with the top edge grits due to a large plastic deformation being generated between the top edge and the workpiece. The main material removal methods of the side edge $\mathrm{CBN}$ grits were rubbing and ploughing, contributing to a small cutting allowance. The elastic deformation of the groove metal became dominant in the material removal. The surface morphology generated by the side edge was remarkably different from that of the transition edge. An obvious boundary could be distinguished on the transition surface, which was crucial for identifying the position of the grinding edge boundary. The surface profile along the green arrow line clarified the location of the boundary line (Fig. 6). A reasonable explanation for this was that the multiple rubbings were produced by a large number of grits located at the side edge.

Figure 7(a) shows the surface morphology images of the failure single-layer electroplated cBN grinding wheel. Figures 7(b)-(e) shows the SEM micrographs of the top edge, the transition edge, the middle of the side edge, and the inner area of the side edge. The surface morphology of the top edge is presented in Fig. 7(b). The micro fracture and the wear flat yielded on the grits during material removal and were the main grinding wheel wear modes. Additionally, only a few grits were pulled out at the top edge of the wheel. At the transition edge on the grinding wheel, a large amount of macro fractures could be observed in the varied CBN grits (Fig. 7(c)). The number of worn grits gradually decreased from grinding wheel flange to the side edge along the radial direction. Severe macro fracture wear of $\mathrm{cBN}$ grits could hardly be found at the displacement of approximate $690 \mu \mathrm{m}$ away from the wheel flange. Figure 7(d) shows the morphology of the middle of the side edge. The micro fracture and the tiny wear flat along with a few grits being pulled out, were generated in the grinding process. Close to the inner area of the side edge, there were a large number of pits generated by grit pullouts (Fig. 7(e)). The grit pullouts represented the main wear mode induced on the grinding wheel at the inner area of the side edge. In addition, the number of the pulled-out grits rose at the inner area of the side edge along the radial direction of the wheel. 
Considering the grinding wheel itself, the maximum undeformed chip thickness in machining is a key factor to determine the ground surface quality. Along the radial direction close to the side edge, the depth of cut corresponding to the grits distributed on the transition edge gradually decreased. For the grits bonded on the side edge, their depth of cut dropped to almost zero. This meant that both the grinding force and the material removal rate were reduced overall. Tiny amounts of metal were removed with the rubbing and ploughing modes, and this led to attrition wear being produced on the active grits as well as the wear flat. The grinding force was redistributed on the $c B N$ grits close to the inner area of the side edge as a principal inducement, and a large number of $\mathrm{CBN}$ grits were pulled out in the grinding process [14]. The redistributed zone of the grinding force was located around a circular region in which the grits were pulled out. The circular region of the inner area of the side edge and the middle of the side edge are marked by the red dashed line circle and the green solid line circle in Fig. 7(a). Only a small number of grits remained in the red dashed line circle, and the number of $\mathrm{CBN}$ grits located in the red dashed line circle was roughly half of that in the green solid line circle. Hence, the grinding force on the $\mathrm{CBN}$ grits at the inner area of the side edge was larger than that of the grits located in the middle of the side edge. Larger grinding force resulted in more grits being pulled out close to the inner area of the side edge. With the increase in the number of grits being pulled out, the phenomenon of grit pullouts was intensified severely, and this led to the concentration of cBN grit pullouts at the inner area of the side edge (Fig. 7(e)). Furthermore, the grinding speed of the grits located at the side edge decreased with the reduction of the wheel rotation radius. An increase in the grinding force was observed. The grit pullouts were aggravated. In the grinding process, the cutting action of the $\mathrm{CBN}$ grit was intermittent in one cutting circle. Alternating reciprocating loads occurred on the grits. Compared with the grinding force of the grits on the top edge, the direction of the grinding force on the transition edge was varied in the continued machining progression. Thus, severe fracture wear was induced on the cBN grits at the transition edge (Fig. 7(c)).

\subsubsection{Micro topography of the worn cBN grits}

To clearly understand the wear behavior of a cBN grit, the morphology of worn grits was tested after grinding. The grinding direction was marked by the blue arrow line. The wear modes of the cBN grits were observed, i.e., micro cracks, macro cracks, wear flat with cleavage fractures, and material adhesion were found. As shown in Fig. 8(a), the macro crack occurred on the cBN grit. The macro crack was a result of the micro cracks growing up to the critical length. The cleavage steps were marked by green straight lines. The main fracture mode of the $\mathrm{CBN}$ grit was cleavage fracture. Based on the width of the crack, the cleavage crack was initiated from the surface of the wear flat. Attrition wear of the top edges of the $c B N$ grit resulted in the wear flat. Meanwhile, Fig. 8(b) shows clear micro cracks on top of the cBN grit. The mechanical tensile stress, as well as the thermal tensile stress, resulted in the micro fractures. A smooth fracture surface was formed due to the micro cracks expansion. Cleavage fracture was induced on the root of the $c B N$ grit, and the $c B N$ debris finally fall off in the grinding process. A magnified image of a cBN grit with a cleavage fracture is shown Fig. 8(c). The fracture surface was characterized by cleavage steps and river patterns. The fracture surface occupied a large part of the whole grit section area and the fracture extended along the normal direction of the nickel bonding layer and close to the bonding layer surface. Material from the workpiece adhered to the top surface of the cBN grit, as indicated in Fig. 8(d).

Page $11 / 28$ 
The EDS results of the adhesive material compositions are presented in Fig. 9. It is worth mentioning that the adhering material was Inconel 718.

\subsubsection{Fracture mechanism of the $\mathrm{cBN}$ grit in the profile grinding process}

Researchers have found that the wear progress of $\mathrm{cBN}$ grits is ductile attrition wear, micro fracturing, and large fracturing with the increase in $\operatorname{AMR}[13,15,24]$. The grits located at the side edge of the grinding wheel rubbed the side surface of the NDG during the creep feed grinding process. Extensive SEM studies have indicated that cleavage fracture is the main fracturing mode of a cBN grit. Cleavage fractures were mainly induced by large grinding force loaded on the $\mathrm{cBN}$ grit. Then cleavage fracturing occurred when the tensile stress was beyond the tensile strength of the grits $[25,26]$. Most of the cBN grits at higher protrusion height were not pulled out due to the high bonding strength and were loaded on large grinding force in grinding process. Figure 10(a) presents a typical cleavage surface on cBN grit. The characteristics of the cleavage fracture were clearly observed such as the cleavage steps, river patterns, and facets. The cleavage cracks could originate from the side surface of a cBN grit. The structural strength of the $\mathrm{cBN}$ grit decreased due to the crack expansion. The upper portion of the grit separated from the grit through cleavage fracturing. Figure 10(b) shows the pits of the pulled-out grits with $c B N$ chips left on the bottom. Cleavage fractures were observed on these residual cBN chips. The regular fracture morphology of the nickel bonding indicated that these grits were not wobbled before fracture occurred and they were toughly bonded. Attrition wear in grinding appears to occur as a result of cBN grits rubbing against a workpiece, and its main characteristic is a wear flat generated on the top surface of grits $[27,28]$. As shown in Fig. $10(\mathrm{c})$, the wear flat was scratched on the top of the grit, and the cBN grits were worn for the condition of reciprocating friction. The grits became dull with the increase in the wear flat area and the grinding force rose. Cleavage fractures occurred on the edge of the wear flat. The number of river patterns increased due to the rivers across the twin boundary (Fig. 10(c)). Figure 10(d) shows the cleavage fractures of the $\mathrm{cBN}$ grit, and the cleavage cracks originated from the crystal boundary. The increase of alternating grinding force accelerated the extension of the cleavage cracks. River patterns occurred on the fracture surface and the river direction was marked by the red arrow line. The grit chips were separated from the grit since the length of cleavage cracks were up to the critical value. Figure 10(e) presents the attrition wear being produced for the cBN grits. The highest cutting edge of the cBN grits was worn out and a wear flat was generated. Cleavage fractures were formed close to the edge of the wear flat. Typical cleavage fractures were observed (marked by the red dash line rectangle). Figure 10(f) shows the cleavage steps and the river patterns of the fracture surface. During the expansion of the cleavage crack, the river pattern tended to merge into a large river to reduce the energy consumption. Thus, the crack source was located on the surface of the grit and the cracks extended along the red arrow line.

\subsection{Wear mechanism of nickel bonding layer for the single- layer electroplated cBN grinding wheel}




\subsubsection{Wear behavior of nickel bonding layer surface}

The failure of the bonding layer also affected the performance of a single-layer cBN grinding wheel [29]. The failure symptoms mainly included cracking, peeling, wear and tear, and corrosion, as evoked in the grinding process. Variations of loads, metal chips, and the fragments of $c B N$ grit gave rise to the electroplated layer failure. The holding strength for the grit was weakened. This was an inducement for the abrasive particles falling from the bonding layer. Figures 11(a)-(c) show the nickel bonding morphology of the failure $\mathrm{CBN}$ wheel. A few pits were formed after the $\mathrm{CBN}$ grits fell away. Few conspicuous scratches could be observed on the pit surface (Fig. 11(a)). According to previous studies $[30,31]$, it is not difficult to understand that the fracture fragments of the grit coupled with the pulled-out particles rubbed and cut the bonding layer as well as the pit surface. The scratches were inevitably generated. Certainly, slight scratches had few negative effects on the bonding strength of the grits. If excessive scratches accumulated in a small area on the electroplated layer, the cracking, peeling, wear and tear of the layer would occur on the grinding wheel. The grits wobbled when under load. Even the joint surface breakage would develop at the interface between the $\mathrm{CBN}$ and the bonding layer. With the degree of grit wobbling being increased, part of the $\mathrm{cBN}$ abrasives were raised and micro cracks were developed around the interface. Then the micro cracks expanded into the bonding layer and the cracks could be observed (Fig. 11(b)). Generally, a slight displacement generated in the metal removal prompted the bonding material around the grit to be squeezed. Plastic deformation in the piled-up metal would cause the bonding layer uplift. The crack was formed when the shear stress exerted by the grit went beyond the allowable strength of the bonding material. The structural integrity of the nickel bonding was damaged, and this resulted in less holding strength of the $c B N$ grit. The wobbled cBN grits were more likely to be pulled out in the following grinding progression. A distinct displacement of the grit occurred and the bonding cracks could be detected around the grit (Fig. 11(c)). A similar phenomenon was observed in the investigation of the single cBN grit cutting experiments [32].

\subsubsection{The section topography of the worn nickel bonding layer}

The section morphology of a fresh wheel is shown in Fig. 12(a). A narrow transition layer could be observed around the matrix. The bonding layer was firmly compacted on the wheel matrix, and the bonding structure was integrated. For the section of the worn wheel, the transition layers were much wider (Fig. 12(b)). The EDS results of the transition layer on the top edge indicated that the compositions of the transition layer were a mixture of $\mathrm{Ni}$ and Fe (Fig. 12(c)). The coefficient of thermal expansion of the transition layer lay between those of the nickel bonding layer $\left(1.30 \times 10^{-5} / \mathrm{K}\right)[33]$ and the wheel matrix $\left(1.16 \times 10^{-5} / \mathrm{K}\right)[34]$. The grinding heat induced different thermal expansion for the nickel bonding layer, transition layer, and wheel matrix, and the nonuniform thermal deformation resulted in different stress values. The N-T boundary (nickel bonding layer and transition boundary) and the M-T boundary (wheel matrix and transition boundary) were generated in the grinding process (Fig. 12(c)). A larger amount of grinding heat led to longer thermal expansion and a wider transition layer. The bonding strength between the bonding layer and the wheel matrix was weakened. Moreover, the grinding force along the radial 
direction was loaded on the wheel filter corner located at the transition edge (Fig. 12(b)). Along the direction of the rotation axis, two symmetric forces of $\mathrm{Ft}$ in opposite directions pressed the bonding layer and the bulge deformation was produced. The EDS results clarified that the partial bonding layer on the top edge peeled off and fractured (Fig. 12(d)). The structural integrity of the bonding layer on the top edge was destroyed and torn, leaving the wheel matrix exposed. The alternating grinding forces loaded on the bonding layer at the transition edge led to cracks developing at the interface around the grits and expanding to the surrounding bonding layer. The bonding chips close to the cracks were warped and fractured (Fig. 12(e)). The bonding layer lost the ability to hold cBN grit. The grit was pulled out in the grinding process (Fig. 12(f)). Warped chips and fractures were observed around the pithead of the pulled out cBN grit.

\section{Conclusion}

In this research, the wear mechanism of a single-layer electroplated cBN grinding wheel was investigated during the creep feed profile grinding NDG of a nickel superalloy. The main results are presented as follows:

(1) Based on the average protrusion height of the $\mathrm{CBN}$ grits located at the side edge, the wear progression of the single-layer electroplated $\mathrm{CBN}$ grinding wheel could be divided into the initial wear stage, the steady wear stage, and the accelerating wear stage. The increase rate of the pulled-out cBN grits remained constant during the entire wear stage. The steady wear stage shared more than $84.6 \%$ of the wheel lifespan. The precision durability of the single-layer electroplated cBN grinding wheel was kept at a high level in the steady wear stage.

(2) The wear modes of the $\mathrm{CBN}$ grit were proven to be attrition wear and cleavage fracture. Large grinding loads on cBN grits that had higher protrusion height or larger area wear flat induced the cleavage fracture. The cleavage cracks might have originated from the wear flat surface or the side surface of the cBN grit.

(3) Joint surface breakage, displacement of grit, and cracks of bonding layer were the inducement for the abrasive particles pulled out from the bonding layer. The transition layer weakened the bonding strength, and bulge deformation of the bonding layer was induced in grinding process. Peeled off of partial bonding layer and warped bonding chips decreased the holding strength of a grit on the single-layer electroplated cBN grinding wheel.

(4) The grinding edges of the single-layer electroplated cBN grinding wheel were defined as the top edge, the side edge, and the transition edge. Severe macro fractures were generated in the cBN grits located at the transition edge due to the alternating loads in the grinding process. The concentration of pulled out grits was observed in the position of the inner area of the side edge. Micro fracture and wear flat were the main wear modes on the top edge and the middle of the side edge.

\section{Declarations}


Authors' contributions Guang Li designed the experiments, finished the data analysis, and completed the paper writing. Professor Guoxing Liang provided the experimental program guidance and revised the draft. Professor Ming Lv and Professor Xingquan Shen guided the analysis of the experimental data, finalized the manuscript, and provided good experimental conditions for the research. Donggang Liu, Xinhui Hao, and Yonggui Huang conducted the experiments and obtained the original experimental data. Mohammed Al-Nehari and Ojiako Tochukwu Princewill completed part of the experimental image processing and carried on the final editing. All of the authors contributed to and approved the final manuscript of this work.

Funding This research was funded by the Natural Science Foundation of Shanxi Province of China (Grant No. 201801D121174) and the Shanxi Provincial Key Research and Development Project of China (Grant No. 201903D121068).

Conflicts of interest/Competing interests The authors declare that there are no potential conflicts of interest.

Availability of data and materials The authors confirm that the data supporting the findings of this study are available within the article.

Code availability Not applicable.

\section{References}

1. Zhu DH, Zhang XM, Ding H (2013) Tool wear characteristics in machining of nickel-based superalloys. Int J Mach Tools Manuf 64:60-77. http://dx.doi.org/10.1016/j.ijmachtools.2012.08.001

2. Miao Q, Ding WF, Kuang WJ, Yang CY (2020) Comparison on grindability and surface integrity in creep feed grinding of GH4169, K403, DZ408 and DD6 nickel-based superalloys. J Manuf Process 49:175-186. https://doi.org/10.1016/j.jmapro.2019.11.027

3. Dai CW, Ding WF, Zhu YJ, Xu JH, Yu HW (2018) Grinding temperature and power consumption in high speed grinding of Inconel 718 nickel-based superalloy with a vitrified CBN wheel. Precis Eng J Int Soc Precis Eng Nanotechnol 52:192-200. https://doi.org/10.1016/j.precisioneng.2017.12.005

4. Ding WF, Xu JH, Chen ZZ, Su HH, Fu YC (2010) Grindability and surface integrity of cast nickel-based superalloy in creep feed grinding with brazed CBN abrasive wheels. Chin J Aeronaut 23:501-510. https://doi.org/10.1016/S1000-9361(09)60247-8.]

5. Pal B, Chattopadhyay AK, Chattopadhyay AB (2010) Development and performance evaluation of monolayer brazed cBN grinding wheel on bearing steel. Int J Adv Manuf Technol 48:935-944. https://doi.org/10.1007/s00170-009-2341-z

6. Ding WF, Xu JH, Chen ZZ, Su HH, Fu YC (2010) Grindability and surface integrity of cast nickel-based superalloy in creep feed grinding with brazed CBN abrasive wheels. Chin J Aeronaut 23:501-510. https://doi.org/10.1016/S1000-9361(09)60247-8 
7. Kopac J, Krajnik P (2006) High-performance grinding-a review. J Mater Process Technol 175:278284. https://doi.org/10.1016/j.jmatprotec.2005.04.010

8. Ichida $Y$ (2008) Mechanical properties and grinding performance of ultrafine-crystalline cBN abrasive grains. Diam Relat Mat 17:1791-1795. https://doi.org/10.1016/j.diamond.2008.01.076

9. Guo C, Ranganath S, Mcintosh D, Elfizy A (2008) Virtual high performance grinding with CBN wheels. CIRP Ann-Manuf Technol 57:325-328. https://doi.org/10.1016/j.cirp.2008.03.071

10. Ding WF, Linke B, Zhu YJ, Li Z, Fu YC, Su HH, Xu JH (2017) Review on monolayer CBN superabrasive wheels for grinding metallic materials. Chin J Aeronaut 30:109-134.

https://doi.org/10.1016/j.cja.2016.07.003

11. Shi Z, Malkin S (2006) Wear of electroplated CBN grinding wheel. J Manuf Sci Eng 128:110-118. https://doi.org/10.1115/1.2122987

12. Upadhyaya RP, Fiecoat JH, Malkin S (2007) Factors affecting grinding performance with electroplated CBN wheels. CIRP Ann-Manuf Technol 56:339-342. https://doi.org/10.1016/j.cirp.2007.05.078

13. Zhao ZC, Fu YC, Xu JH (2016) Behavior and quantitative characterization of CBN wheel wear in highspeed grinding of nickel-based superalloy. Int J Adv Manuf Technol 87:3545-3555. https://doi.org/10.1007/s00170-016-8686-1

14. Yu TY, Bastawros AF, Chandra A (2017) Experimental and modeling characterization of wear and life expectancy of electroplated CBN grinding wheels. Int J Mach Tools Manuf 121:70-80. https://doi.org/10.1016/j.jimachtools.2017.04.013

15. Naik DN, Mathew NT, Vijayaraghavan L (2019) Wear of Electroplated Super Abrasive CBN Wheel during Grinding of Inconel 718 Super Alloy. J Manuf Process 43: 1-8. https://doi.org/ 10.1016/j.jmapro.2019.04.033

16. Naskar A, Choudhary A, Paul S (2020) Wear mechanism in high-speed superabrasive grinding of titanium alloy and its effect on surface integrity. Wear, 462-463 (January 2020): 203475. https://doi.org/10.1016/j.wear.2020.203475

17. Miao Q, Li HN, Ding WF (2020) On the temperature field in the creep feed grinding of turbine blade root: Simulation and experiments. Int J Heat Mass Transf 147 (June 2019): 118957. https://doi.org/10.1016/j.ijheatmasstransfer.2019.118957

18. Miao Q, Ding WF, Kuang WJ, Xu JH (2020) Tool wear behavior of vitrified microcrystalline alumina wheels in creep feed profile grinding of turbine blade root of single crystal nickel-based superalloy. Tribol Int 145 (October 2019): 106144. https://doi.org/10.1016/j.triboint.2019.106144

19. Zhao ZC, Fu YC, Xu JH, Zhang ZW, Liu ZW, He J (2016) An investigation on high-efficiency profile grinding of directional solidified nickel-based superalloys DZ125 with electroplated CBN wheel. Int J Adv Manuf Technol 83:1-11. https://doi.org/10.1007/s00170-015-7550-z

20. Zhao ZC, Qian N, Ding WF, Wang Y, Fu YC (2020) Profile grinding of DZ125 nickel-based superalloy: Grinding heat, temperature field, and surface quality. J Manuf Process 57:10-22. https://doi.org/10.1016/j.jmapro.2020.06.022 
21. Guo C, Shi Z, Attia H, Mclntosh D (2007) Power and wheel wear for grinding nickel alloy with plated CBN wheels. CIRP Ann-Manuf Technol 56:343-346. https://doi.org/10.1016/j.cirp.2007.05.079

22. Aspinwall DK, Soo SL, Curtis DT, Mantle AL (2007) Profiled superabrasive grinding wheels for the machining of a nickel based superalloy. CIRP Ann-Manuf Technol 56:335-338. https://doi.org/10.1016/j.cirp.2007.05.077

23. Zhang Y, Kong C, Davidsen RS, Scardera G, Duan LP, Khoo KT, Payne DNR, Hoex B, Abbott M (2020) 3D characterisation using plasma FIB-SEM: A large-area tomography technique for complex surfaces like black silicon. Ultramicroscopy 218 (May 2019):113084.

https://doi.org/10.1016/j.ultramic.2020.113084

24. Fujimoto $M$, Ichida $Y$ (2008) Micro fracture behavior of cutting edges in grinding using single crystal cBN grains. Diam Relat Mat 17:1759-1763. https://doi.org/10.1016/j.diamond.2008.03.008

25. Gao SW, Yang CY, Xu JH, Su H, Fu YC, Ding WF (2018) Wear behavior of monolayer-brazed CBN wheels with small diameter during internal traverse grinding. Int J Adv Manuf Technol 94:12211228. https://doi.org/10.1007/s00170-017-0875-z

26. Ding WF, Zhu YJ, Zhang LC, Xu JH, Fu YC, Liu WD, Yang CY (2015) Stress characteristics and fracture wear of brazed cBN grains in monolayer grinding wheels. wear 332-333:800-809. https://doi.org/10.1016/j.wear.2014.12.008

27. Li P, Jin T, Xiao H, Chen ZQ, Qu MN, Dai HF, Chen SY (2020) Topographical characterization and wear behavior of diamond wheel at different processing stages in grinding of N-BK7 optical glass. Tribol Int 151 (February 2020): 106453. https://doi.org/10.1016/j.triboint.2020.106453

28. Li GX, Yi S, Wen CE, Ding SL (2018) Wear mechanism and modeling of tribological behavior of polycrystalline diamond tools when cutting Ti6Al4V. J Manuf Sci Eng-Trans ASME 140 (April 2018): 121011. https://doi.org/10.1115/1.4041327

29. Bhaduri D, Chattopadhyay AK (2010) Effect of pulsed DC CFUBM sputtered TiN coating on performance of nickel electroplated monolayer cBN wheel in grinding steel. Surf Coat Technol 204:3818-3832. https://doi.org/10.1016/j.surfcoat.2010.04.063

30. Ding WF, Xu JH, Chen ZZ, Su HH, Fu YC (2010) Wear behavior and mechanism of single-layer brazed CBN abrasive wheels during creep-feed grinding cast nickel-based superalloy. Int J Adv Manuf Technol 51:541-550. https://doi.org/10.1007/s00170-010-2643-1

31. Okumiya M, Tsunekawa Y, Saida T, Ichino R (2003) Creation of high strength bonded abrasive wheel with ultrasonic aided composite plating. Surf Coat Technol 169:112-115.

https://doi.org/10.1016/S0257-8972(03)00176-2

32. Li XK, Wolf S, Zhu TX, Zhi G, Rong YM (2015) Modelling and analysis of the bonding mechanism of CBN grains for electroplated superabrasive tools-Part 1: Introduction and application of a novel approach for determining the bonding force and the failure modes. Int J Adv Manuf Technol 76:2051-2058. https://doi.org/10.1007/s00170-014-6411-5

33. Zhang B, Li XB, Li D (2013) Assessment of thermal expansion coefficient for pure metals. Calphad 43:7-17. https://doi.org/10.1016/j.calphad.2013.08.006 
34. Shi ZY, Li X, Duan NM, Yang QB (2021) Evaluation of tool wear and cutting performance considering effects of dynamic nodes movement based on FEM simulation. Chin J Aeronaut 34:140-152. https://doi.org/10.1016/j.cja.2020.08.003

\section{Figures}

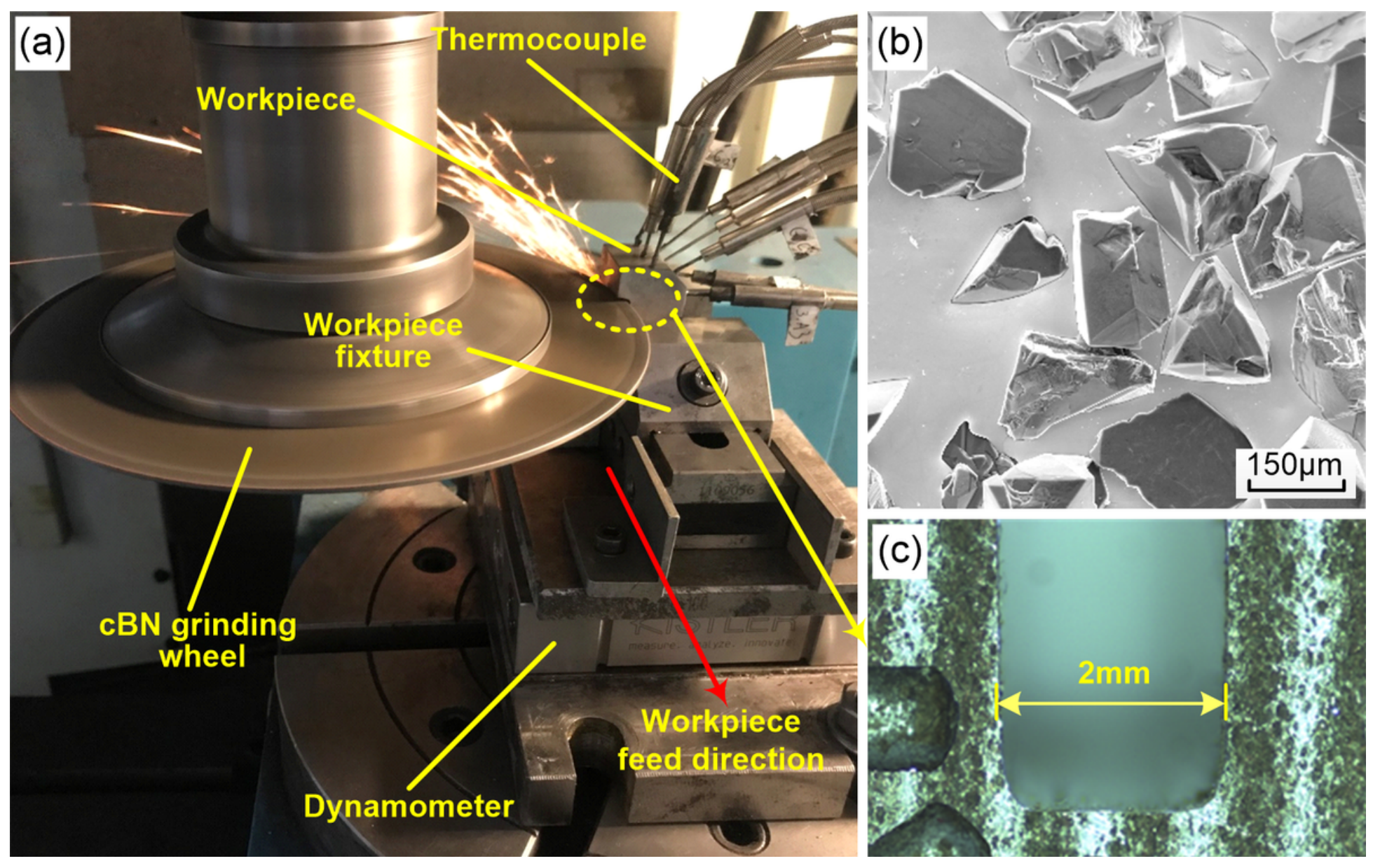

Figure 1

Detailed information for the experiment setup: (a) experiment setup, (b) as-received grinding wheel surface topography, (c) section of the NDG 


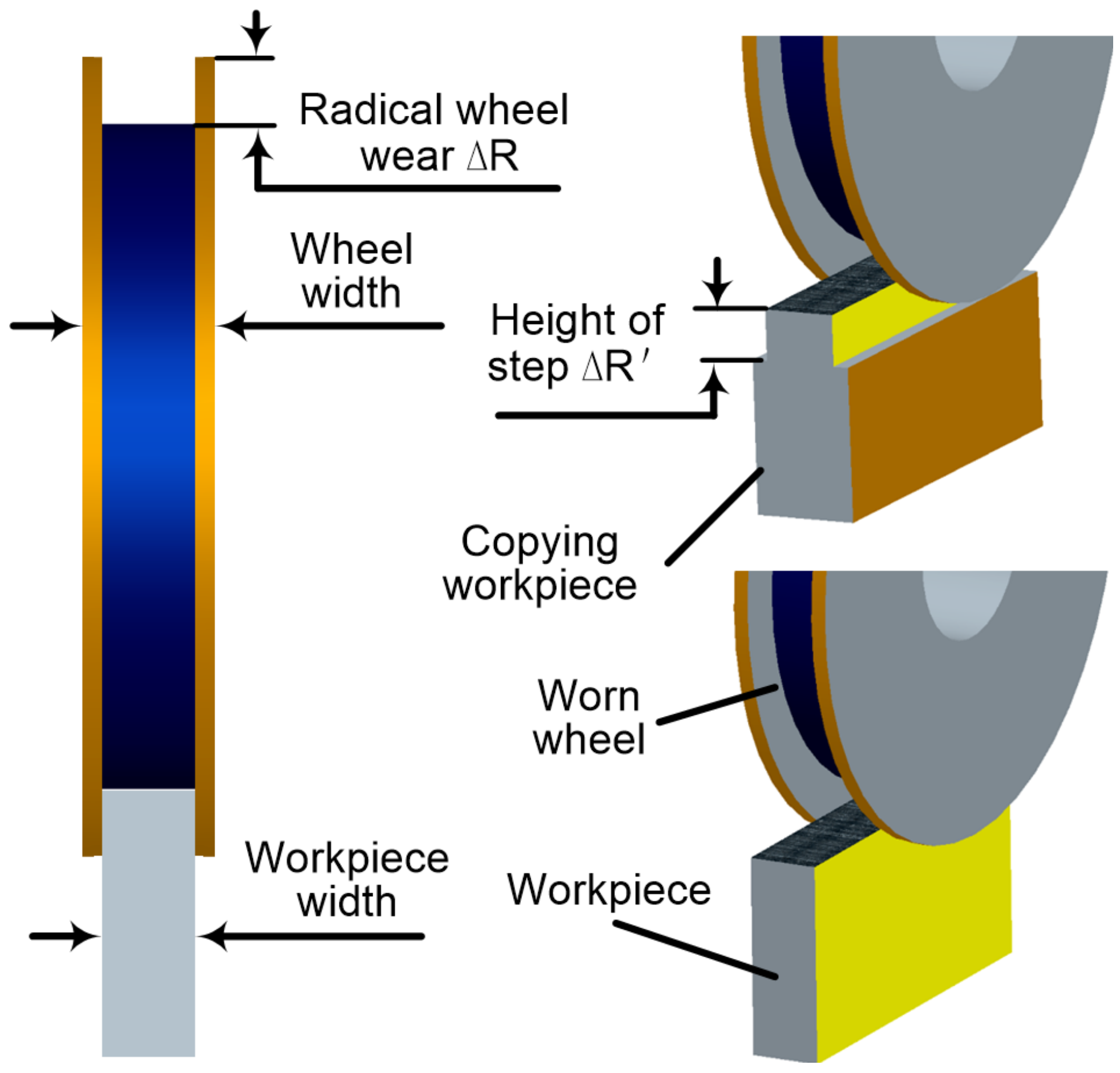

Figure 2

Radial wear measurement in surface grinding 

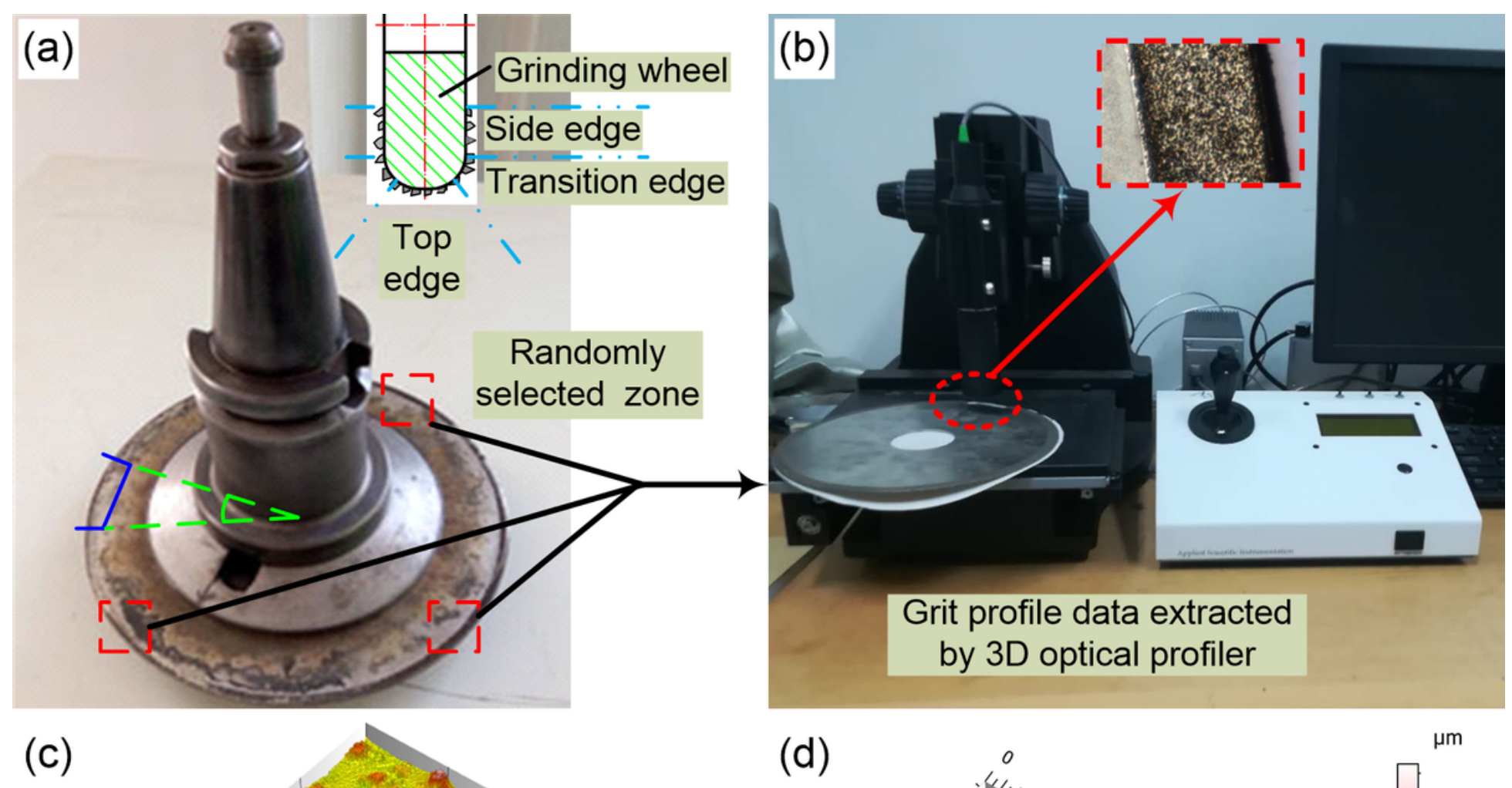

(c)

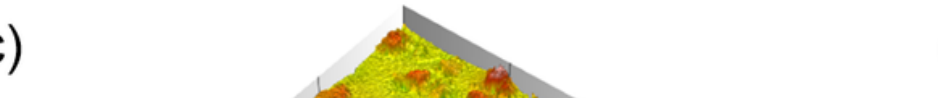

(d)

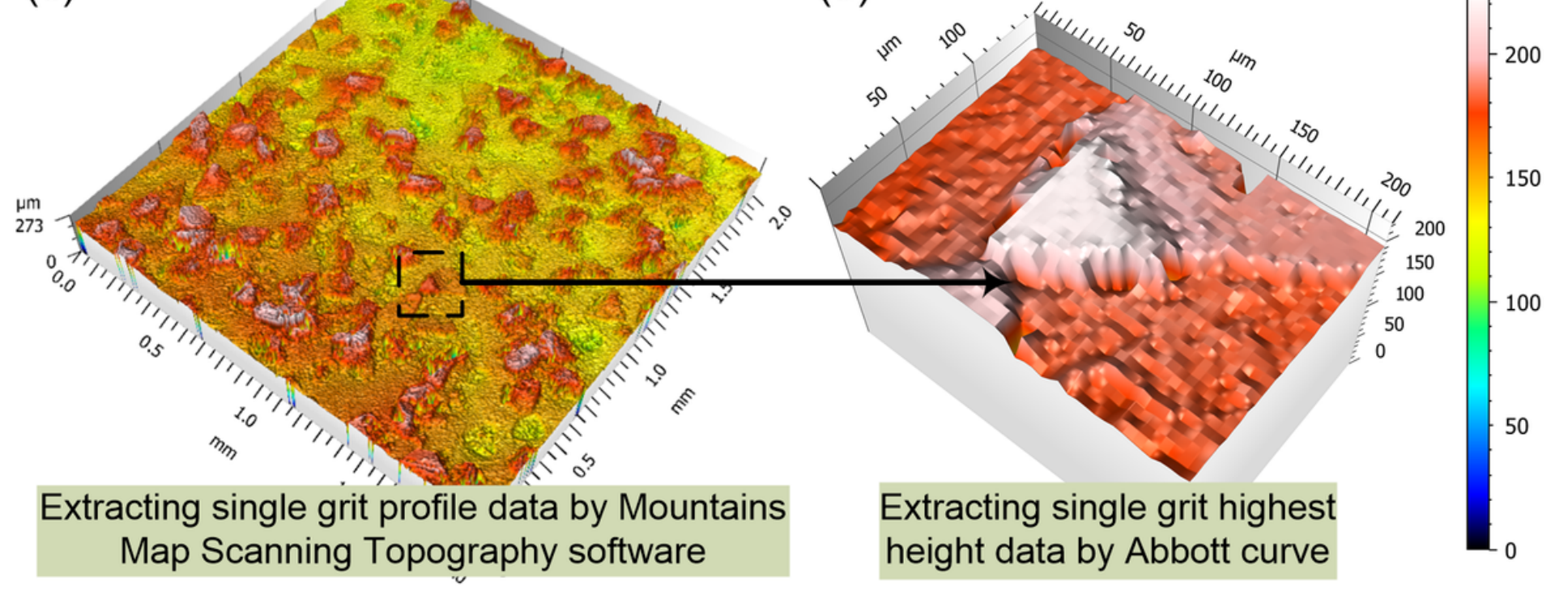

\section{Figure 3}

Measurement process of cBN grit protrusion height: (a) worn single-layer electroplated cBN grinding wheel, (b) 3D optical profiler, (c) 3D profile of the side edge, (d) 3D profile of single cBN grit 

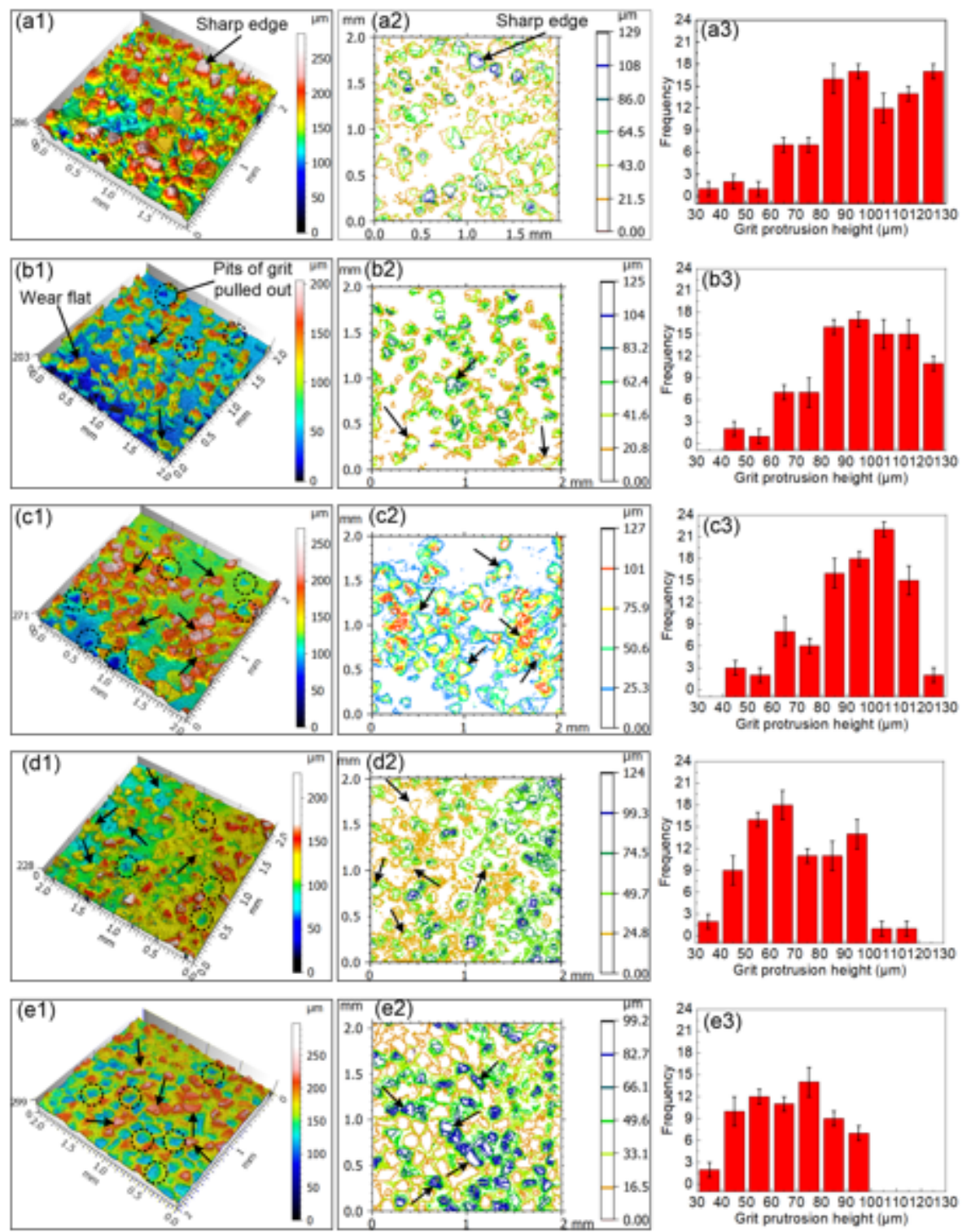

Figure 4

The wear evolution of the wheel surface with the increase in AMR volume $(\mathrm{Va}=0 \mathrm{~mm} 3, \mathrm{Vb}=834.6 \mathrm{~mm}$, $V c=1669.2 \mathrm{~mm} 3, \mathrm{Vd}=3338.4 \mathrm{~mm} 3, \mathrm{Ve}=5424.9 \mathrm{~mm} 3):(\mathrm{a} 1)-(\mathrm{e} 1) 3 \mathrm{D}$ geomorphology results of the grinding wheel, (a2)-(e2) grit height contours in 2D, (a3)-(e3) statistical average frequency histograms for the grit protrusion height 

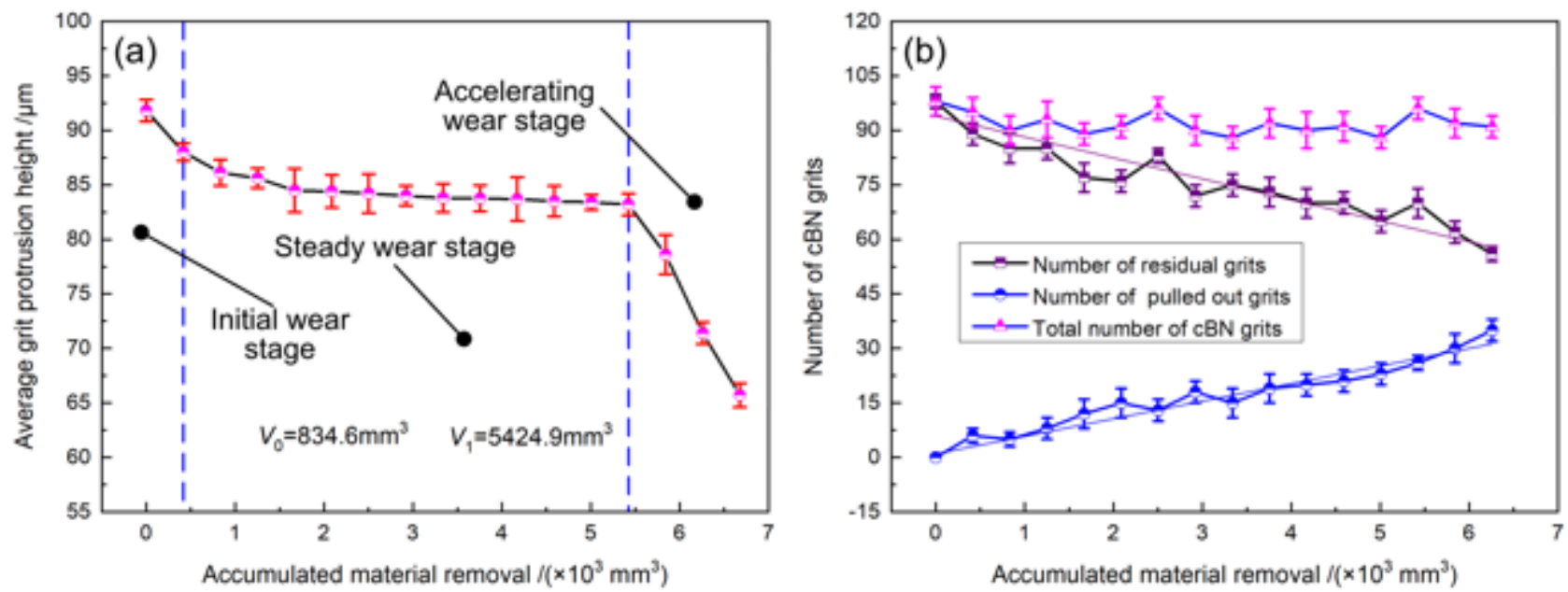

Figure 5

Data details of the detected cBN grits on the side edge with the increase in AMR: (a) average grit protrusion height, (b) number of residual grits and the number of pulled out grits

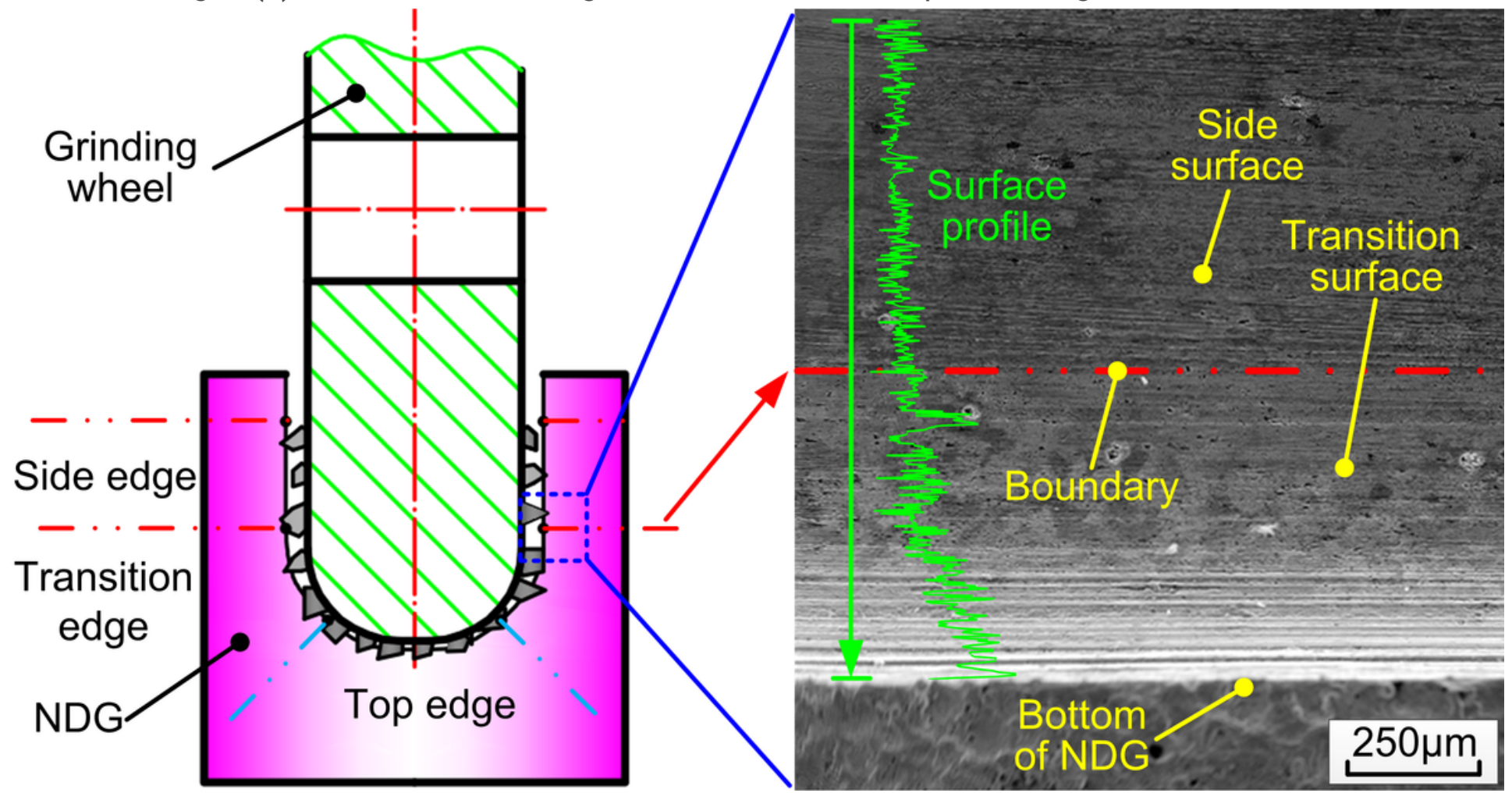

Figure 6

Grinding edge division of the single-layer electroplated cBN grinding wheel. 

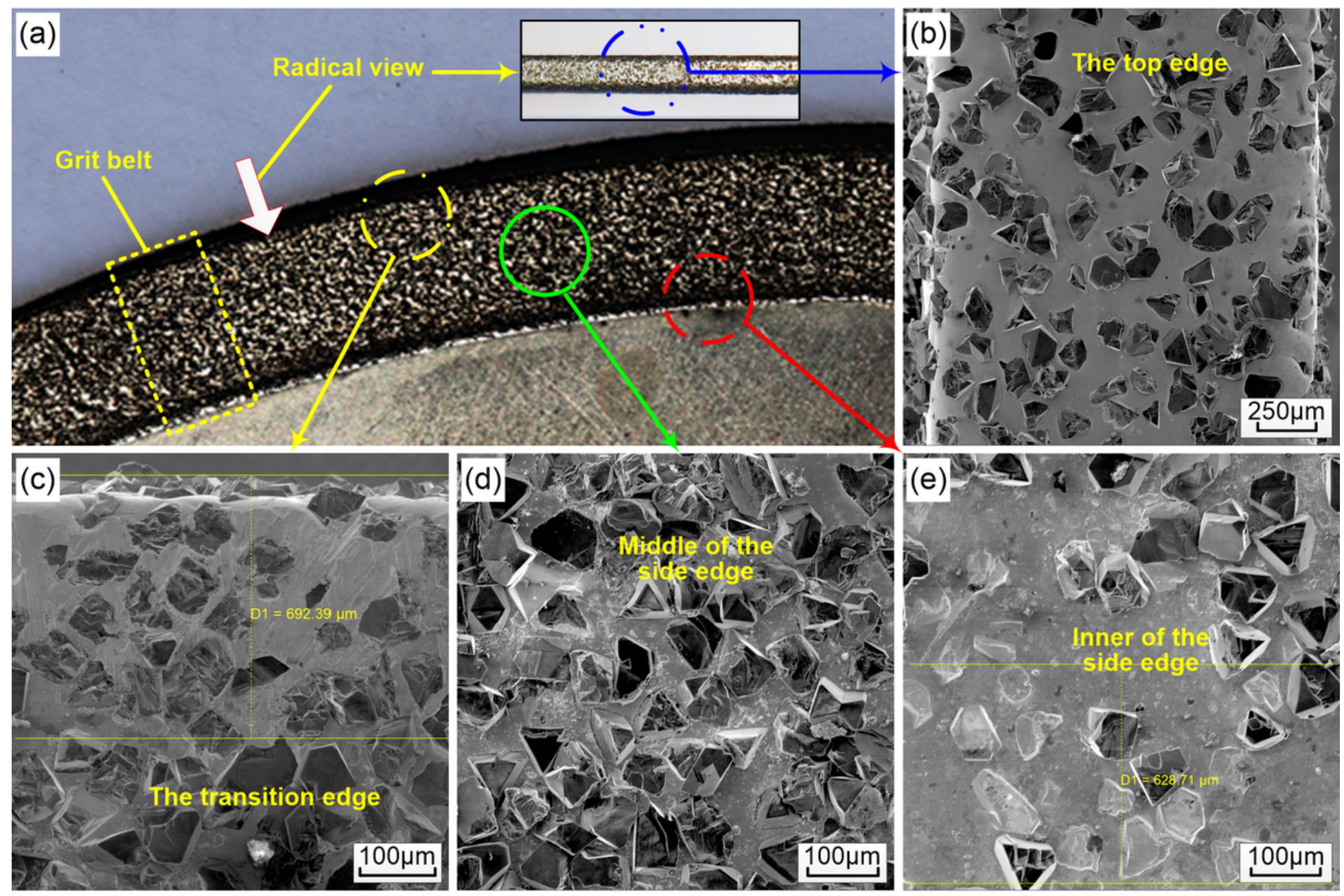

\section{Figure 7}

Topography of the worn grinding wheel: (a) macro photograph of cBN grit belt, (b) top edge, (c) transition edge, (d) middle of the side edge, (e) inner area of the side edge 

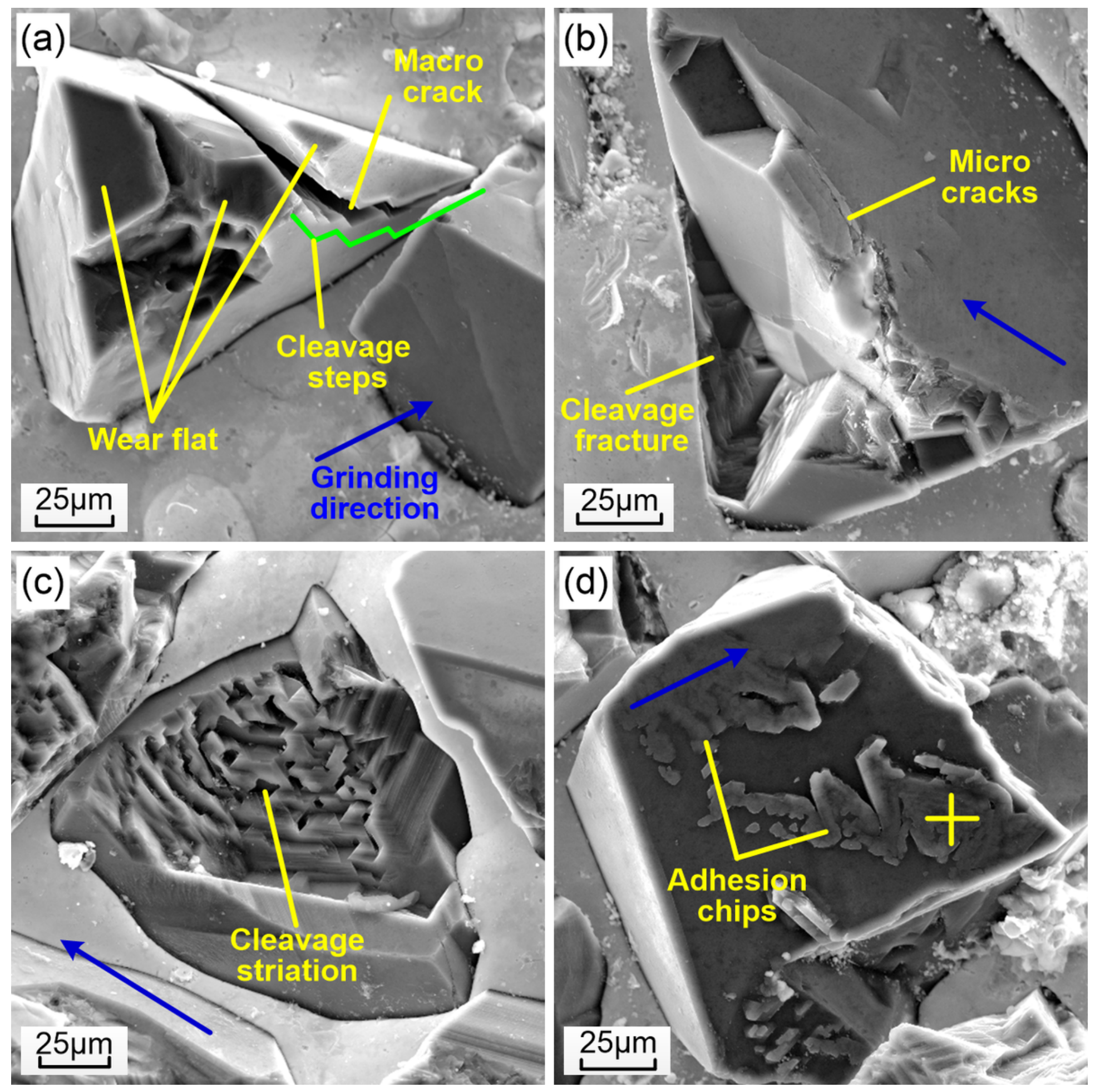

Figure 8

SEM images of the worn $\mathrm{CBN}$ grits on the side edge of the single-layer electroplated cBN grinding wheel:

(a) grit with macro cracks, (b) micro cracks on grit, (c) cleavage fractures on grit, (d) cBN grit with material adhering 


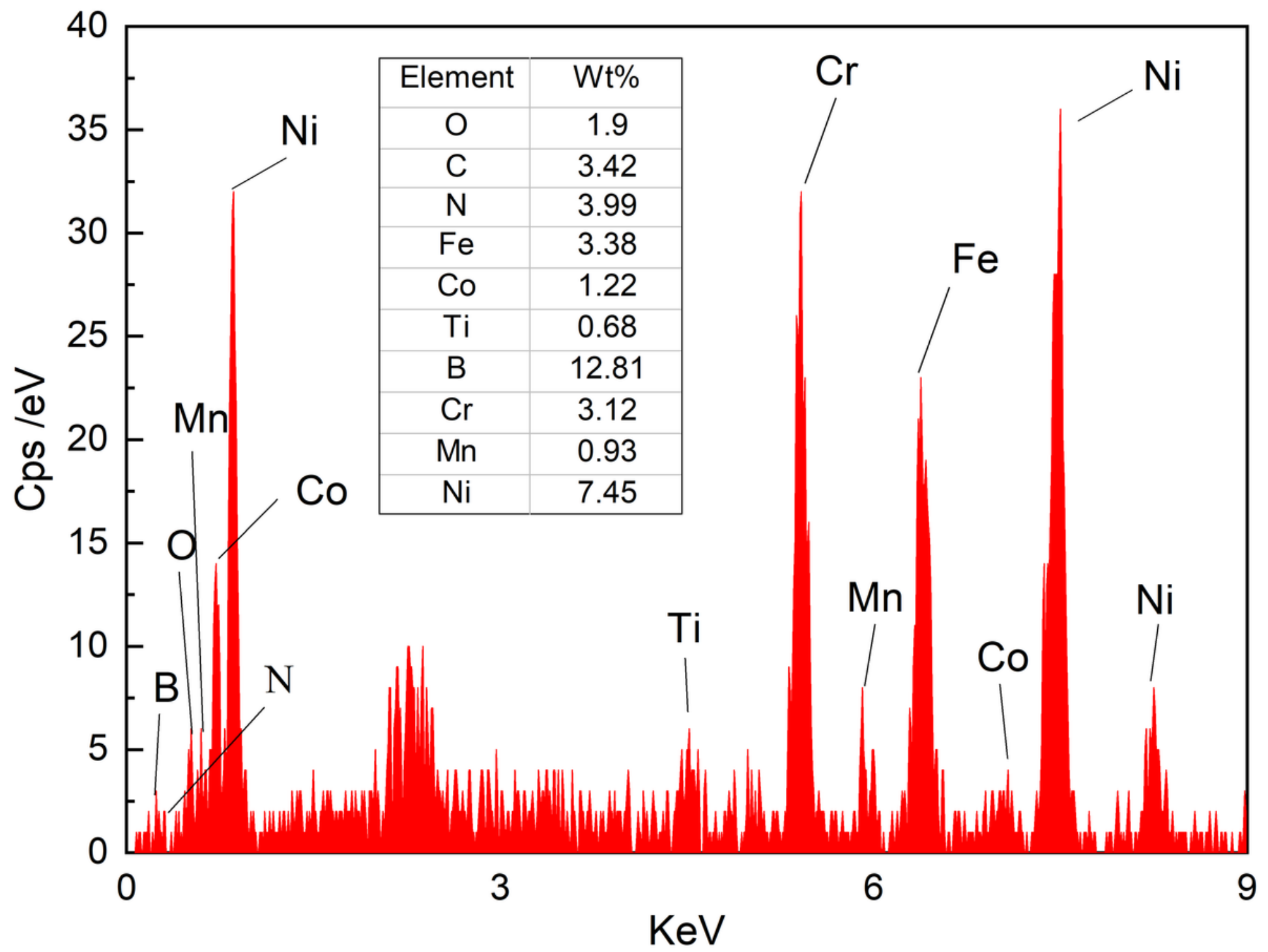

Figure 9

EDS results of the material adhering to the grit. 
(a)
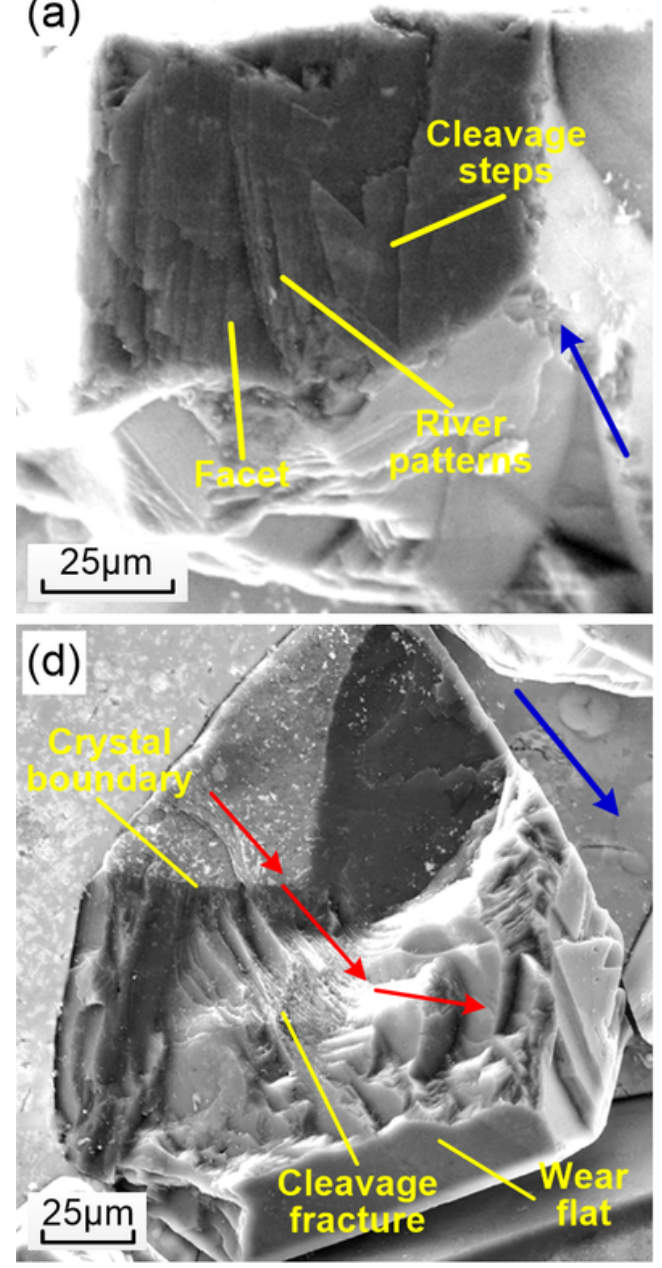
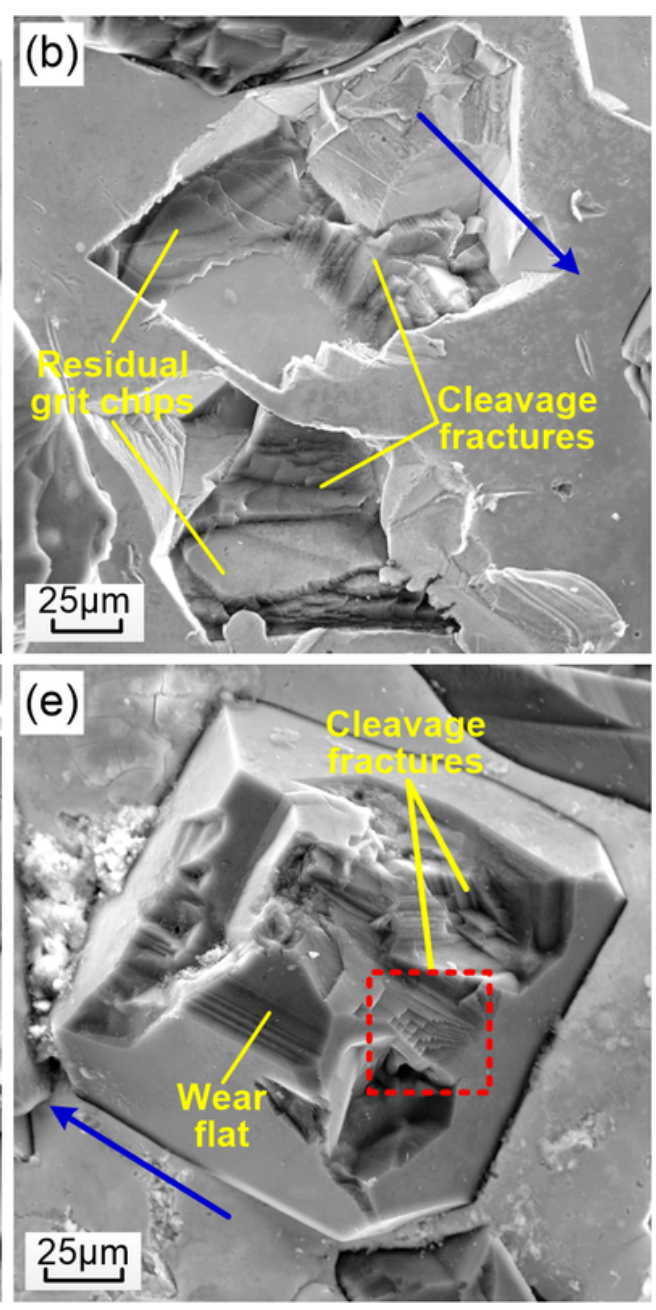
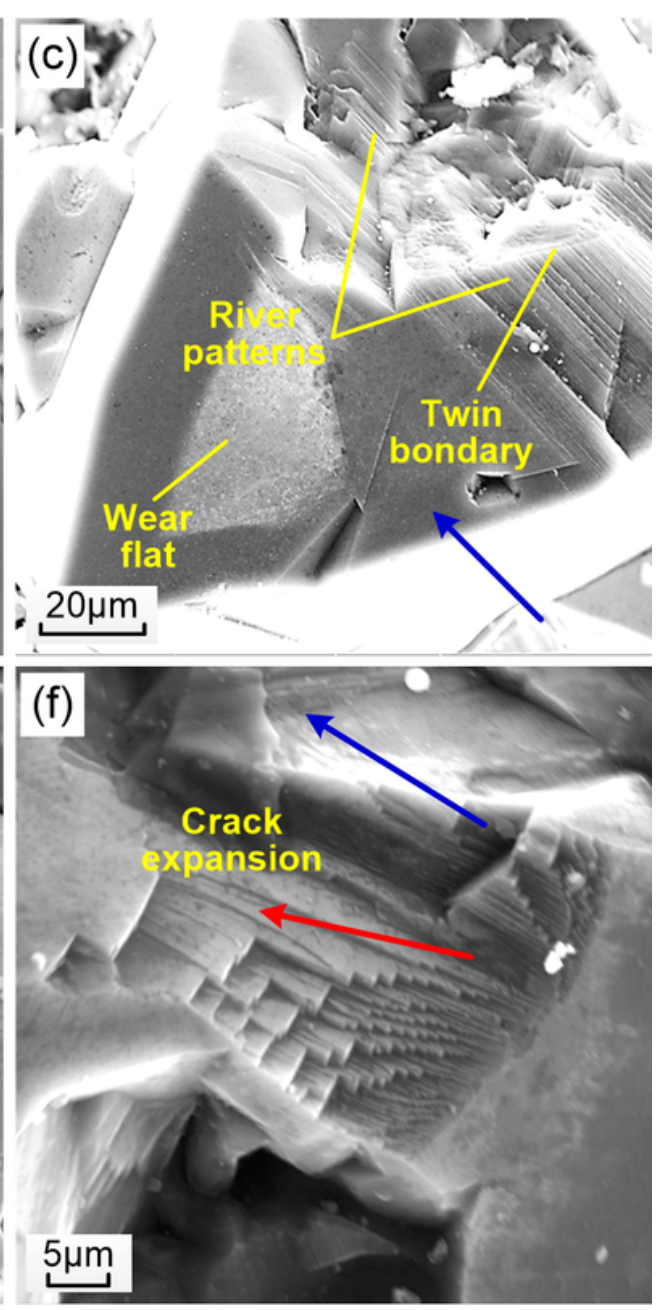

Figure 10

Cleavage fractures of the $\mathrm{CBN}$ grits: (a) typical cleavage surface on the grit, (b) cleavage fractures on the residual cBN chips, (c) cleavage fractures on the edge of the wear flat, (d) cleavage fractures originated from the crystal boundary, (e) cleavage fractures originated from the side surface of the cBN grit, (f) source of cleavage fractures
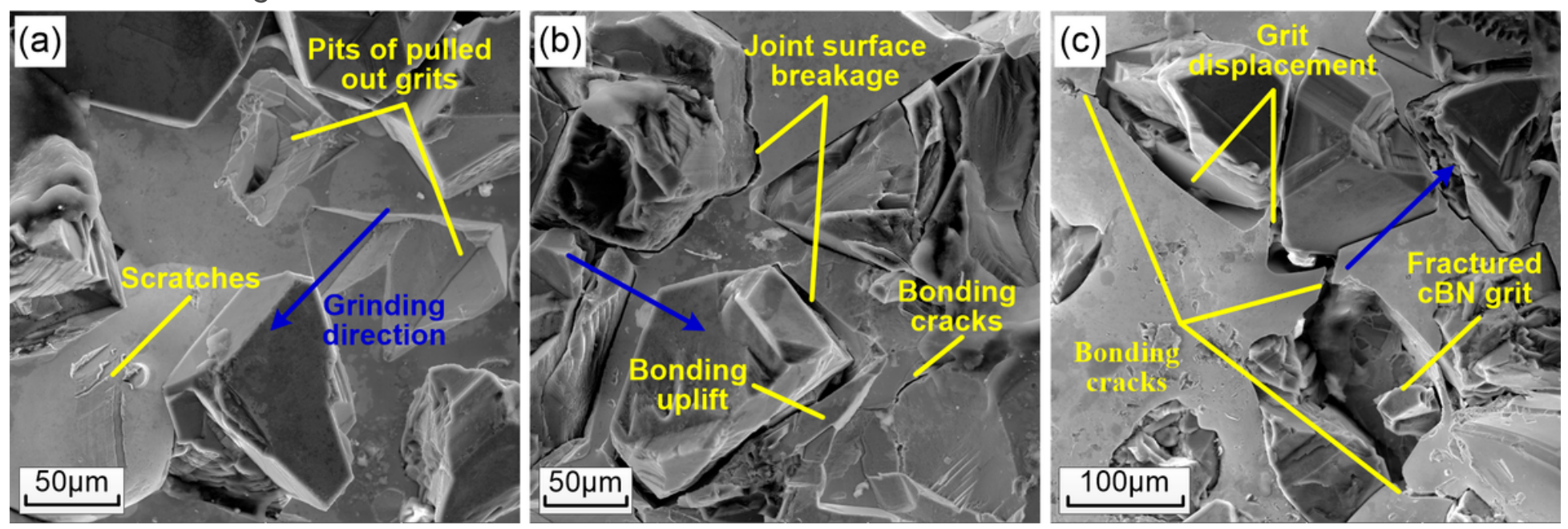

Figure 11 
Wear modes of nickel bonding surface: (a) bonding scratches and pits, (b) joint surface breakage and bonding uplift, (c) grit displacement and bonding cracks

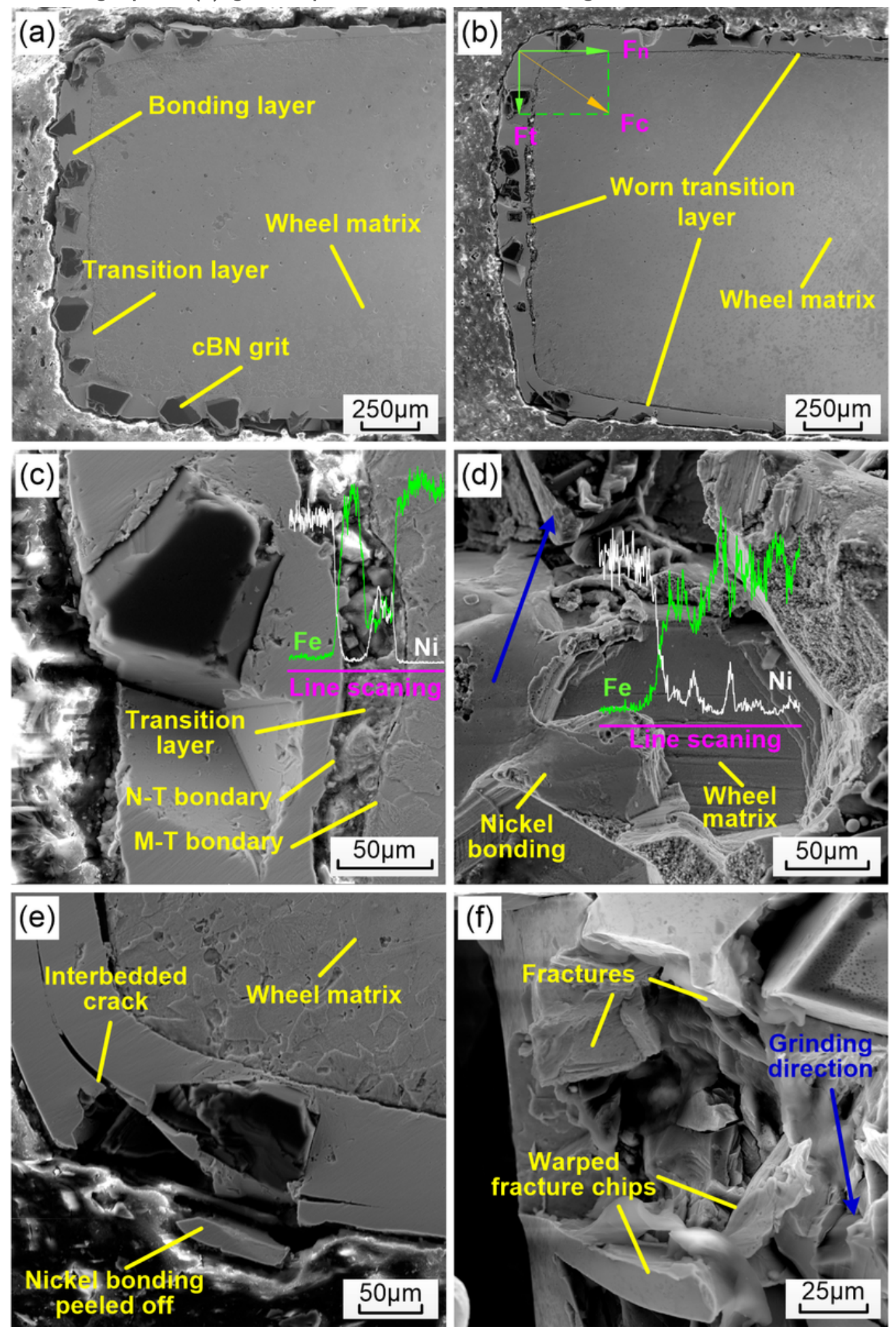

Figure 12

Wear features of the nickel bonding: (a) section of the as-received single-layer electroplated cBN grinding wheel, (b) section of the worn single-layer electroplated cBN grinding wheel, (c) transition layer, (d) 
bonding layer that peeled off, (e) interbedded cracks at the transition edge, (f) warped fracture chips of bonding layer 